\title{
México contemporáneo: un panorama a partir de sus aspectos ambientales, políticos y sociales
}

\section{Contemporary Mexico: an outlook based on its environmental, political and social aspects}

\author{
José Galindo (COORd.) (20I 8), MÉxico CONTEMPORÁNEO: ASPECTOS \\ ECONÓMICOS, POLITIICOS Y SOCIALES, UNIVERSIDAd VeraCRUZANA, \\ MÉXICO, 49I PP, ISBN: 978-607-502-708-I
}

Se trata de una obra de la Universidad Veracruzana que traduce y actualiza los artículos que fueron publicados originalmente bajo el título Mexico in focus: political, enviromental, and social issues por Nova Science Publishers en el 2015. Los temas analizados, como bien lo refleja su título, son económicos, políticos y sociales, aunque también incluye una amplia reflexión sobre lo ambiental. El libro se organiza en tres secciones precedidas por una introducción a cargo del coordinador.

Es una obra coherente en la que los capítulos no son enunciativos y la organización propuesta no es sumatoria de temas, sino una presentación integrada en un panorama que permite entender la situación del México contemporáneo.

Trece capítulos son escritos por expertos nacionales y extranjeros de larga trayectoria, quienes abordan objetos de estudio desde diferentes disciplinas científicas y analizan tanto las particularidades de México como los cambios profundos experimentados en la historia de nuestro país en los dos últimos siglos.

La primera parte del libro se conforma por cuatro capítulos en los que se revisa la dimensión ambiental de los problemas del México contemporáneo; en un primer momento con énfasis en la preocupación por la rápida y caótica urbanización de la Cuenca de México, a la que califica como una de las transformaciones más profundas sufrida en una región natural en el mundo; posteriormente toca temas transversales a la problemática ambiental como son los bosques, el agua y los residuos.

El primer capítulo, "Energía, medio ambiente y sociedad en la cuenca de México hasta el siglo XIX", es de Germán Vergara, quien 
elabora una descripción de la historia ambiental de la cuenca de México desde la llegada de los primeros seres humanos, hace aproximadamente 10 mil años, hasta 1850. Su intención es presentar la forma en que se ha modificado esta región geográfica a partir de una descripción detallada de la transformación crucial -experimentada desde el paso de una sociedad agraria hacia otra industrial- con el objetivo de comprender cómo la transición energética dio forma a la relación entre seres humanos y al ambiente de la cuenca.

El segundo capítulo, a cargo de Jonathan Graham, se denomina "La unión hidrológica entre el valle del Mezquital y la cuenca de México en el largo plazo"; en éste, el autor aborda la importancia de la cuestión hidrológica vista en su interdependencia, desde cuya visión enfatiza que la relación marcada por desigualdades y ambigüedades ha conducido a la formación de dos de los distritos de riego más importantes de México -en la región más árida del centro del país-a la par de considerables problemas medioambientales para su población, debido al uso de las aguas capitalinas que convirtieron sus vegas en el sistema más grande y antiguo en aprovechar aguas negras para el riego.

No todos los capítulos de esta primera parte abordan los problemas de la zona centro del país ni se enfocan en el tema del agua; el tercer capítulo es una contribución de Fernando Pérez Montesinos, "Tierra, bosques y pueblos en la meseta purépecha, 1869-1911”, que trata uno de los temas más importantes de la construcción histórica, política y social de México: el reparto de las tierras, para lo cual elabora un análisis cuidadoso de las reformas agrarias del estado de Michoacán.

Para este autor, "el reparto", más que referirse al fenómeno de conversión de los derechos comunales de la tierra en derechos de propiedad individual, se refiere a un proceso de transformaciones en la forma en que los pueblos purépechas poseían, usaban y se beneficiaban de sus tierras; debe entenderse como origen de trastornos notables en el uso y disfrute de la tierra, así como los bosques, pero también como un fenómeno que dio lugar a giros y vaivenes inesperados para los pueblos de la meseta.

Cierra esta primera sección de reflexión sobre lo ambiental, el capítulo "Impulsando a México a una cultura de reciclaje" de Virginia Montiel Corona y José Antonio Guevara García, quienes dan un giro a la reflexión de los temas clásicos de la problemática ambiental y construyen un panorama actualizado y crítico del reciclaje en el país.

Los autores caracterizan la situación del manejo de los residuos sólidos en México; dan cuenta de las carencias legales, financieras y humanas que aquejan a los municipios para su tratamiento; apuntalan las bondades económicas y ambientales así como las ventajas sociales del reciclaje y documentan los esfuerzos que se emprenden en pro de esta actividad 
desde el sector gubernamental, la iniciativa privada, las organizaciones civiles, las universidades y los grupos de pepenadores.

La siguiente sección de la obra se dedica a la reflexión de los aspectos sociales del México contemporáneo. El hilo conductor que vincula la primera parte del libro y la exposición de tópicos socioeconómicos es la cuestión del agua. Mikael Wolfe -en su capítulo "El agua de la Revolución: auge y caída de un derecho socioambiental en México" - propone un análisis histórico de la acción gubernamental en el sector y con ello un amplio espectro de análisis temporal y conceptual.

$\mathrm{Su}$ foco de estudio son los derechos sociales y ambientales emanados de la revolucionaria Constitución de 1917, tan ambiguos como contradictorios, donde al mismo tiempo que se confiere el derecho popular de acceso y uso de los recursos de la Nación, se otorga a ésta la responsabilidad de su conservación. Entre los derechos socioambientales, el autor se enfoca en el agua y su deterioro tanto social como ambiental.

El capítulo sexto comienza la reflexión sobre los aspectos puntuales de la vida social del país. "Clubismo en el México posrevolucionario: un análisis sobre la emergencia de los clubes sociales y de servicio en Puebla y en Tijuana, 1920-1960", presentado por David Tamayo, nos conduce a mirar un fenómeno surgido en los espacios urbanos posrevolucionarios. Englobados bajo en término "clubismo", Tamayo cimienta los debates en torno a las asociaciones cívicas en México y, haciendo referencia tanto a clubes sociales como de servicio, señala su contribución en la creación de vínculos sociales, en el fortalecimiento del capital social, en la conducción de acciones cívicas y en el fomento a la democracia. Su trabajo concluye señalando la decadencia de la membresía a los clubes en la sociedad mexicana contemporánea y ofrece líneas de reflexión que vinculan este declive con la pérdida del tejido social.

Los capítulos siete y ocho están estrechamente relacionados; en el primero, "Sistema de protección social universal: un instrumento de política pública para alcanzar mayor movilidad social en México", Roberto Vélez Grajales y Juan Enrique Huerta Wong plantean que en un país con baja movilidad social, como México, la construcción de un sistema de protección social universal que garantice un piso mínimo de bienestar para la población es un instrumento de política capaz de reducir la desigualdad de oportunidades e incrementar las opciones de movilidad social ascendente para quienes parten de una condición desventajosa.

Posteriormente, Alejandro Villagómez en "Cobertura de pensiones en México" hace una valoración de la problemática de la protección al ingreso de la población adulta mayor y los retos de política pública que ésta plantea, señala que los cambios demográficos experimentados han conducido al 
envejecimiento de la población mexicana, fenómeno que no se ha acompañado de programas públicos de pensiones contributivas.

El autor analiza estos programas, sus características, cobertura y problemas, así como los programas de protección al ingreso mínimo o transferencias y propone una valoración de la problemática en el marco de la economía mexicana, caracterizada por un enorme mercado informal y con un acentuado dinamismo y movilidad de los trabajadores entre el sector formal e informal de empleo. Su análisis apuntala la necesidad de un programa de pensión universal coherente a los esquemas contributivos actuales.

El último de los capítulos de esta sección sobre los aspectos sociales está a cargo de José Galindo. En "El origen de la Comisión Nacional de Derechos Humanos en 1990, en el proceso de democratización latinoamericana ¿una institución de la sociedad mexicana o del Estado mexicano?", el autor analiza el origen y evolución de dicho organismo.

Galindo hace una revisión crítica de la historia de la Comisión y apunta que es consecuencia de las necesidades económicas y políticas de un régimen deslegitimado. Asimismo, al reconstruir su evolución y caracterizar la transición de la $\mathrm{CNDH}$ como un organismo desconcentrado -altamente dependiente del poder ejecutivo- a un organismo descentralizado -con menor control vertical- y finalmente hacia un organismo constitucional autónomo en la gestión y aspectos presupuestarios -con personalidad jurídica y patrimonio propios- el autor cuestiona su rendimiento social y concluye que en dicha autonomía, sin controles ni contrapesos, con una marcada subutilización de funciones, el organismo dista de cumplir adecuadamente su objetivo primordial de defender los derechos de las personas.

La tercera sección del libro se integra por tres artículos y se destina a la reflexión sobre los aspectos políticos del México contemporáneo. Las dos primeras contribuciones tienen como elemento común de análisis uno de los factores más importantes para comprender nuestra realidad política: el régimen del partido revolucionario institucional.

En su capítulo "La crisis de la democracia en México: violencia, política y movimientos sociales", Alberto J. Olvera ubica que desde mediados de 2014 el país sufre una crisis política y moral tan grave como la ocurrida entre 1994 y 1995. Para el autor, el régimen priista logró salir de aquella crisis mediante una serie de acciones desesperadas; después de veinte años, dichas acciones que agotaron sus potenciales estabilizadores se vuelven insuficientes para encarar la actual, que califica como una crisis múltiple: económica, política, moral y social.

Para entender su origen y posibles salidas, Olvera analiza las limitaciones de la transición democrática y, con ello, la continuidad institucional del viejo régimen; estudia la aceleración de la crisis desde el regreso del PRI y presenta la evolución y los retos estratégicos de los nuevos 
movimientos sociales y de protesta, así como los posibles derroteros de la lucha que se libra entre la restauración autoritaria y la democratización.

El siguiente capítulo, "Los orígenes de los partidos de oposición mexicanos y sus estrategias de movilización del voto", de José Antonio Hernández Company, es una reflexión sobre el fenómeno político más importante de la década de los noventa: la democratización del sistema político.

Al estudiar la transición democrática mexicana, el autor enfoca su atención en las estrategias utilizadas por los partidos de oposición para llamar al voto. De tal suerte que Hernández Company estudia primeramente la formación de los partidos políticos, a los que clasifica como programáticos y clientelares. Posteriormente, argumenta que las estrategias electorales adoptadas por los partidos políticos están relacionadas con el ambiente que éstos enfrentaron en su origen, lo que permite entender que los cambios en el sistema electoral de la década de los noventa condujeron a los partidos políticos a adoptar estrategias más efectivas.

Cierra esta sección, y el libro, una contribución de Andrew Paxman, quien en su capítulo "Televisa de 1997 a 2018: el socio fallido de la democratización” recupera un debate universal que pone en el centro de atención, el potencial de las grandes corporaciones de medios para efectuar la captura del Estado, lo que les permite dirigir los procesos políticos para favorecer sus intereses comerciales e ideológicos.

En este marco, el autor retoma el poder mediático de la televisora mexicana en relación con su influencia política y la capacidad de decisión que tuvo en la vida política mexicana; sin embargo, concluye que dichos poder y capacidades están en vilo debido a cuestiones financieras, a la futura competencia en el mercado y a cuestiones políticas.

Como todo libro compilado, la sugerencia es leerlo en función de los intereses particulares; sin embargo, una vez comenzada la lectura el lector descubrirá que la coherencia de la obra anima a adentrarse más y más en la revisión de otros temas.

La intención de quien escribe esta reseña es presentar esta obra a la comunidad académica, dado que constituye un trabajo cuyo aporte es significativo para comprender la realidad ambiental, social y política de nuestro México contemporáneo.

Nancy Merary Jiménez Martínez njimenez@crim.unam.mx Investigadora de tiempo completo Centro Regional de Investigaciones Multidisciplinarias (CRIM-UNAM) 
Nancy Merary Jiménez Martínez. Doctora en Estudios Urbanos y Ambientales por El Colegio de México. Actualmente es investigadora asociada "C" de tiempo completo en el Centro Regional de Investigaciones Multidisciplinarias de la UNAM, en el Laboratorio de Estudios sobre el Gobierno de una Universidad Sustentable del Programa Estudios en Gobierno y Políticas Públicas. Es parte del Sistema Nacional de Investigadores, nivel I. Sus líneas de investigación son la sustentabilidad universitaria, la gestión de residuos y la política pública ambiental. Entre sus últimas publicaciones destacan, como autora: "Hacia basura cero: auditoria al Programa de manejo integral de residuos sólidos universitarios en el CRIM-UNAM en 2019", Encuentro de Expertos en Residuos Sólidos. Encuentro académico sobre residuos plásticos y microplásticos, 12 (1), Calimaya, Sociedad Mexicana de Ciencia y Tecnología Aplicada a Residuos Sólidos, A. C. pp. 21-29 (2019); "El modelo de gestión de residuos en Mazatepec, Morelos", Revista Legislativa de Estudios Sociales y de Opinión Pública, 12 (24), Ciudad de México, Cámara de Diputados/Centro de Estudios Sociales y de Opinión Pública, pp. 11-35 (2019); como coautora, "Hacia la construcción de un perfil sociodemográfico de los pepenadores en Cuernavaca: una vulnerabilidad de base económica”, en Maria Zanin; Carolina Valente Santos y José Antonio Guevara García (coords.) Catadoras e catadores de materiais recicláveis e a perspectiva social dos residuos sólidos urbanos: casos do México e Brasil, Sáo Carlos, Diagrama Editorial, pp. 60-82 (2019). 